\title{
"SOMOS TODXS CLÁUDIA": A LEGITIMAÇÃO DA VIOLÊNCIA PELO ESTADO*
}

\author{
Dantielli Assumpção Garcia** \\ Lucília Maria Abrahão e Sousa ${ }^{* \star}$ \\ Universidade de São Paulo \\ Faculdade de Filosofia, Ciências e Letras \\ Ribeirão Preto, SP, Brasil
}

\begin{abstract}
Resumo: Este texto, na perspectiva teórica da Análise de Discurso pecheutiana, analisa alguns posts publicados nas páginas do Facebook da Marcha das Vadias sobre o assassinato de Cláudia da Silva Ferreira após ter sido arrastada por uma viatura da Polícia Militar em 16 de março de 2014 no Rio de Janeiro. Mobilizando a noção de acontecimento discursivo, mostramos como se atualiza uma memória sobre o negro e a polícia no Brasil, colocando esta como culpada pelo assassinato da população negra e aquele como vítima da sociedade segregacionista. Explicitamos como nos posts há a tentativa de uma ruptura na violencia produzida e legitimada pelo Estado.
\end{abstract}

Palavras-chave: Negro. Polícia. Acontecimento discursivo.

\section{DIZERES INICIAIS: O CASO CLÁUDIA}

Neste texto, sob a perspectiva teórica da Análise de Discurso pêcheutiana, mobilizando a noção de acontecimento discursivo (GUILHAUMOU, MALDIDIER, 1993; PÊCHEUX, 1990; ZOPPI-FONTANA, 1997), analisamos alguns posts que circularam, durante o mês de março de 2014, nas páginas do Facebook da Marcha das Vadias sobre a morte de Cláudia da Silva Ferreira após ter sido arrastada, no dia 16 de março de 2014, por uma viatura da Polícia Militar do Rio de Janeiro. Esse acontecimento, noticiado pela mídia, gera uma mobilização nas redes sociais, principalmente em páginas do Facebook, pela "desmilitarização da polícia" e pela "humanização da população negra e pobre brasileira". Nas páginas da Marcha das Vadias, diversas são as formulações compartilhadas que intentam compreender esse acontecimento.

O movimento feminista Marcha das Vadias surgiu a partir de um episódio ocorrido em janeiro de 2011, quando o policial canadense Michael Sanguinetti, em uma

\footnotetext{
* Este texto faz parte do projeto de Pós-Doutorado A Marcha das Vadias nas redes sociais: efeitos de feminismo e mulher, financiado pela FAPESP (proc. no 2013/16006-8), que tem como objetivo central analisar a formulação, a constituição e a circulação de um discurso sobre a mulher e o feminismo na contemporaneidade e no ciberespaço.

** Doutora em Estudos Linguísticos - Universidade Estadual Paulista Júlio de Mesquita Filho. Bolsista FAPESP (proc. n 2013/16006-8). E-mail: dantielligarcia@gmail.com.

*** Livre-docente em Ciências da Informação e da Documentação. Professora Colaboradora da UFSCar. Bolsista CNPq e FAPESP. Email: luciliamsr@uol.com.br.
} 
palestra na Universidade de Toronto, Canadá, recomendou que "as mulheres evitassem se vestir como putas para não serem vítimas de estupro". Como reação a essa fala que culpabiliza a vítima, em abril do mesmo ano cerca de três mil canadenses saíram às ruas para protestar na primeira SlutWalk, a Marcha das Putas, ou na tradução adotada no Brasil, a Marcha das Vadias. Esse movimento rapidamente se espalhou pelo mundo, sendo também realizado em diversas cidades brasileiras. O movimento da Marcha das Vadias entre suas reivindicações luta pela igualdade entre os gêneros, pelo fim da violência contra a mulher, por uma posição legitimada a esta na sociedade contemporânea. Formulações sobre o assassinato de Cláudia da Silva Ferreira circularam em postagens da Marcha das Vadias por ter como vítima de uma violência produzida e legitimada pelo Estado uma mulher, e refletir sobre isso faz parte das lutas feministas.

Nosso trabalho, com o objetivo de analisar o modo como um fato pontual (a morte de Cláudia) apresenta-se como um acontecimento discursivo a partir do momento em que permite a emergência de um novo enunciado - "Somos todxs Cláudia" - e enunciase a polícia como culpada, divide-se em três partes. Na primeira, discorremos sobre a noção de acontecimento discursivo, diferenciando-o do acontecimento jornalístico. $\mathrm{Na}$ segunda parte, refletimos sobre a posição do negro no Brasil. Na terceira, analisamos os posts publicados nas páginas do Facebook da Marcha das Vadias. Desse modo, pretendemos analisar como há a atualização de uma memória sobre o negro pobre no Brasil do século XXI e como outros sentidos atribuídos à polícia emergem nas formulações sobre a morte de Cláudia que circulam na sociedade e no ciberespaço. De instituição que protege o cidadão, a polícia passa a ser vista como uma organização criminosa, que mata "pretos e pretas pobres", que é racista, que é machista.

O discurso compartilhado pela Marcha das Vadias afirma que há uma legitimação da violência e esta é produzida pelo Estado. Há a sustentação, pelo Estado Repressor, que se diz democrático, e pela mídia, de um discurso/memória que coloca o negro/a negra pobre como culpados pela violência que sofrem, pois estes estão aliados ao tráfico, à criminalidade, são "bandidos", "marginais": "Acharam que minha mãe era bandida" (fala de uma das filhas de Cláudia), "Mulher arrastada temia que filhos fosse confundidos com traficantes" (Manchete de jornal). O que os movimentos sociais tentam fazer é romper com essa memória e fundar/atualizar um discurso em que haja a inscrição do sujeito negro/negra em outras regiões de sentidos. O sujeito negro/negra pobre, nas formulações divulgadas pela Marcha das Vadias, é inscrito na posição de vítima da violência produzida pelo Estado. $O$ criminoso não é o negro/a negra, mas sim a polícia, o Estado que produz "atrocidades", que é "responsável pelo genocídio do povo negro e pobre do Brasil" (Compartilhamento da Marcha das Vadias de São Paulo da página do Facebook Rede de Comunidades e Movimentos contra a Violência). Por meio desses compartilhamentos no ciberespaço, é possível notar as relações entre os movimentos (sociais) que lutam/militam pelo fim da violência. Como mostramos em outro trabalho (GARCIA; SOUSA, 2014, p. 91), as páginas do Facebook da Marcha das Vadias funcionam como um arquivo constituído por textos, vídeos, campanhas publicitárias, fotos. Esses materiais se dividem em dois tipos: um produzido pela Marcha das Vadias e divulgado nas páginas do movimento e outro elaborado por outros movimentos sociais, outros sujeitos, não necessariamente militantes da Marcha das Vadias, e que são divulgados nas páginas por meio de links; desse modo, 
"compartilham-se saberes, dizeres produzidos por outros sujeitos, movimentos, mas que sustentam lutas travadas pela Marcha das Vadias" (GARCIA; SOUSA, 2014, p. 91).

Assim, a Marcha das Vadias usa o ciberespaço e a rede para fazer circular outros sentidos ao negro/negra no Brasil. O ciberespaço se constituirá, portanto, como um espaço da (ciber)militância, no qual se buscará, como dispõem os movimentos sociais, "resgatar a dignidade do negro roubada por criminosos" (Página do Facebook Think Olga). Ao analisarmos os posts publicados e divulgados nas páginas da Marcha das Vadias, intentamos verificar como há atualização de uma memória sobre o negro/negra no Brasil e a tentativa de ruptura da violência produzida e legitimada pelo Estado repressor brasileiro.

\section{ACONTECIMENTO DISCURSIVO: ATUALIZANDO UMA MEMÓRIA}

Antes da análise sobre o acontecimento em si, é necessário tecer algumas considerações acerca das noções de acontecimento jornalístico e acontecimento discursivo.

Apresentado nos jornais em forma de notícias, o acontecimento jornalístico compreende um fato selecionado entre os diversos que ocorrem em um dado momento, considerado de interesse público e que, em virtude disso, passa a ocupar as edições diárias dos noticiários impressos ou eletrônicos: "Trata-se de um acontecimento enquanto referente, com uma existência material no mundo, um acontecimento enquanto um fato que se inscreve na história do dia a dia, que o jornal e os jornalistas se propõem a escrever" (DELA-SILVA, 2011, p. 151).

A morte de Cláudia da Silva Ferreira funciona como um acontecimento jornalístico enquanto um fato que se inscreve na história do dia a dia da sociedade. Os jornais, ao noticiarem esse fato, produziram sentidos a esse acontecimento, interpretando-o de um modo a desumanizar a vítima ao não a nomear ou enunciá-la como "arrastada", "mulher", "moradora":

Como pontua Dela-Silva (2011, p. 152),

o dizer jornalístico não traz consigo o fato, mas um gesto de interpretação do mesmo. A imprensa, mais que simplesmente narrar acontecimentos e servir de suporte para tais narrações, produz sentidos para os acontecimentos que elege como de destaque em um momento dado (DELA-SILVA, 2011, p. 152).

É por causa do modo como o dizer jornalístico interpreta e narra o fato que os movimentos sociais produzem diferentes formulações à morte de Cláudia. Mostrando que a "mulher arrastada" tem nome, outros enunciados surgem, entrecruzando-se, e produzindo um acontecimento discursivo em que é possível enunciar "Somos todxs Cláudia". Será esse enunciado, com um enunciador coletivizado pelo "nós" oculto - nós movimentos sociais, nós mulheres, nós negros, nós Marcha das Vadias -, que fará funcionar o acontecimento discursivo, o qual humaniza, identifica a vítima e culpabiliza a polícia.

\footnotetext{
${ }^{1}$ Essas notícias foram veiculadas pelo site $<$ g1.globo.com> em 17 de março de 2014.
} 
Figura 1 - Notícias

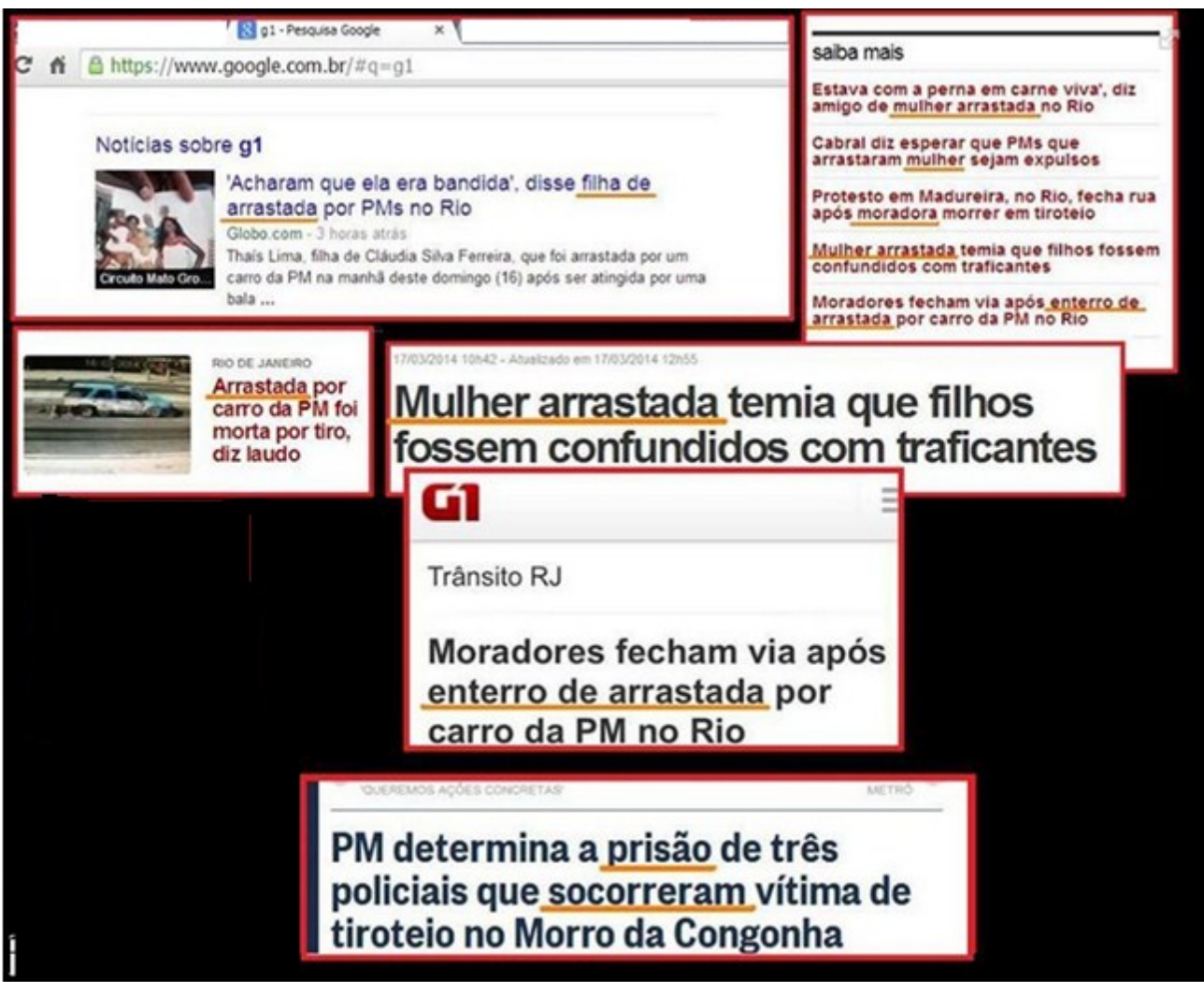

Segundo Pêcheux (1990, p. 19) o acontecimento discursivo é aquele que se produz no ponto de encontro entre uma memória e uma atualidade. No entrecruzamento de enunciados, faz-se trabalhar "o acontecimento (o fato novo, as cifras, as primeiras declarações) em seu contexto de atualidade e no espaço de memória que ele convoca e que já começa a reorganizar" (PÊCHEUX, 1990, p. 19). O enunciado "Somos todxs Cláudia", as notícias jornalísticas, as postagens que circulam nas páginas do Facebook da Marcha das Vadias, por meio de compartilhamentos de outras páginas, fazem trabalhar um acontecimento discursivo. Nesses enunciados entrecruzados, há a tentativa de atualizar uma memória sobre o negro no Brasil e organizar os dizeres para que haja a compreensão de um fato tão violento como "uma mulher ser arrastada por uma viatura da polícia militar”. Para Guilhaumou e Maldidier (1993, p. 165-166),

\footnotetext{
O acontecimento discursivo não se confunde nem com a notícia, nem com o fato designado pelo poder, nem mesmo com o acontecimento constituído pelo historiador. Ele é apreendido na consistência de enunciados que se entrecruzam em um momento dado (GUILHAMOU; MALDIDIER, 1993, p. 165-166).
}

Dessa forma, ao acontecer a morte de Cláudia, inúmeros dizeres, sustentados pelo enunciado "Somos todxs Cláudia", passarão a circular no espaço urbano e no ciberespaço. Esses buscam produzir um entendimento sobre essa violência. Temos desde notícias jornalísticas, as quais dizem o fato se colocando em uma posição de "desumanização" da vítima, até campanhas artísticas, as quais buscam retratar Cláudia como cidadã, como um ser humano com sonhos e medos. Esses dizeres enunciativos se 
entrecruzam e produzem um acontecimento discursivo, o qual busca romper com um dizer que coloca o negro em uma posição de responsável pela violência que sofre e a polícia como protetora e salvadora. Souza (2003), ao analisar o discurso fundador da afirmação do negro no Brasil, aponta que:

\begin{abstract}
Fatos linguísticos e fatos polêmicos definem, segundo a ótica discursiva, uma estrutura de enunciação. Apreender os sentidos produzidos nesta articulação é abordar o discurso como acontecimento. Sob este aspecto, o discurso deve ser visto como o processo de produção de sentidos provenientes do confronto de forças analisáveis segundo coordenadas históricas de tempo, espaço e posições de poder (SOUZA, 2003, p.60).
\end{abstract}

No confronto entre uma memória sobre o negro, em um espaço segregacionista como o Brasil, funcionando diferentes posições de poder (polícia, traficante, morador da favela), a tentativa de produzir sentidos ao enunciar-se "Somos todxs Cláudia" e não uma "mulher arrastada". De um sujeito sem nome a um movimento que sustenta seus dizeres no ciberespaço e interpela os sujeitos que ali navegam a militarem pela causa "humanizadora" de Cláudia da Silva Ferreira.

Zoppi-Fontana (1997, p. 51) afirma que o acontecimento discursivo é o ponto de encontro de uma memória e de uma atualidade a partir da qual se reorganizam as práticas discursivas. A autora (1997, p. 51) salienta que o acontecimento discursivo funciona como o ponto de quebra dos rituais enunciativos, como

\begin{abstract}
a ruptura de uma prática discursiva pela transformação dos rituais enunciativos que a definem; a interrupção de um processo de reformulação parafrástica de sentidos pela mudança das condições de produção; enfim, a emergência de um enunciado ou de uma posição enunciativa novos que reconfiguram o discurso, e através deste participam do processo de produção do real histórico. (ZOPPI-FONTANA, 1997, p. 51).
\end{abstract}

Temos, como condição de produção dos enunciados sobre a morte de Cláudia da Silva Ferreira, o espaço de uma favela carioca, Morro da Congonha, em Madureira. Conforme o acontecimento jornalístico, Cláudia da Silva Ferreira "foi baleada no dia 16 de março em uma operação da Polícia Militar e arrastada pelo carro da corporação após ter sido socorrida" ${ }^{2}$. Esse acontecimento faz funcionar uma memória da favela ocupada pela polícia como uma tentativa de acabar com o tráfico. Nesse espaço do morro, diversas posições (de poder) estão em confronto. Há a polícia, os traficantes, os moradores. A morte da ajudante de serviços gerais, moradora da favela, circulará, ao ser noticiada pelos jornais, em espaços além da favela. Ao circular, essas relações de confronto são explicitadas e (res)significadas. Nos dizeres jornalísticos, Cláudia será mais uma vítima, sem nome, da violência urbana. Nos dizeres dos movimentos sociais, Cláudia é mulher "guerreira", "batalhadora", "determinada". A polícia, nas notícias, estava socorrendo a vítima. Já, para os coletivos, a polícia é "assassina" (compartilhamento da Marcha das Vadias de São Paulo), culpada pela morte de Cláudia.

\footnotetext{
${ }^{2}$ Em < g1.globo.com/rio-de-janeiro/noticia/2014/04/delegado-explica-reconstituicao-da-morte-de-claudiasilva-ferreira-no-rio.html>. Acesso em 09 fev. 2015.
} 
As postagens nas páginas do Facebook da Marcha das Vadias sobre o caso Cláudia funcionam como um acontecimento discursivo, em que se intenta interromper um processo de reformulação parafrástica (em que se sustenta um dizer sobre a mulher negra pobre habitante da favela) e permitir a emergência de enunciados, da posiçãosujeito-militante que luta para que nenhuma mulher seja vítima de violência, nos quais se busca romper com uma naturalização da violência contra o "segundo sexo" 3 . Na ruptura, o discurso-outro surge como memória, todavia, os movimentos sociais buscam atualizá-la e reorganizar sua prática discursiva, fazendo falar outra posição de um outro lugar que clama por uma "desmilitarização da polícia" (Marcha das Vadias de Recife, 17 de março de 2014) e por uma "humanização da população negra e pobre brasileira" (Compartilhamento da Marcha das Vadias de São Paulo da página do Facebook Rede de Comunidades e Movimentos contra a Violência, 17 de março de 2014).

\title{
3 O NEGRO NO BRASIL: O QUE PODE ESSE SUJEITO?
}

Nesta parte de nosso texto, faremos uma breve reflexão sobre a posição do negro no Brasil. Essa reflexão nos auxiliará a compreender as condições de produção de um discurso sobre esse sujeito no Brasil do século XXI a partir do acontecimento da morte de Cláudia da Silva Ferreira.

Ao analisarmos a história do negro e da posição por ele ocupada na história do Brasil, é possível observar que se sustentam dizeres que colocam o negro como uma "coisa" que pode ser descartada, arrastada; como um marginal, bandido. O negro ocupa ainda na sociedade brasileira uma posição segregada, marcada por seu passado histórico.

A história do negro brasileiro traz como fato a escravidão, a qual, em solos tupiniquins, durou mais de 300 anos. Conforme Mattoso (1982), os escravos que aqui aportaram vinham de diferentes lugares: Guiné (século XVI), Congo e Angola (século XVII), Costa do Marfim (século XVIII), Angola e Moçambique (século XVIII/XIX). Como aponta Silva Filho (2006, p. 104-105):

\begin{abstract}
O tráfico Atlântico ou "a travessia da Calunga Grande", acontecida entre os séculos XVI e XIX e considerado a maior experiência de diáspora compulsória de seres humanos, envolveu o tráfico de cerca de 15 milhões de homens, mulheres e crianças africanas, arrancados de suas terras e transportados para as Américas e para a Europa. De acordo com diversas pesquisas, cerca de $40 \%$ dos escravos africanos traficados vieram para o Brasil, mais de 4 milhões de indivíduos, representando a principal força de trabalho e constituindo a grande maioria da população dos períodos Colonial e Imperial da nossa história política e social (SILVA FILHO, 2006, 104-105, grifos do autor).
\end{abstract}

Ressalta Silva Filho (2006, p. 106) que a escravidão como comércio, visando ao lucro, entre os africanos, só tem início no século XV, "quando da chegada dos lusitanos ao continente, iniciando o tráfico negreiro e incentivando os traficantes europeus, que

\footnotetext{
${ }^{3}$ Expressão de Simone de Beauvoir ([1949] 1970), na qual a autora busca discutir as relações tensas, estabilizadas na sociedade, entre homens e mulheres. O "segundo sexo", na sociedade patriarcal, seria a mulher.
} 
ofereciam presentes aos reis ou chefes tribais [...] em troca de prisioneiros.". A partir desse momento, como aponta Florentino (1997, p. 31, apud SILVA FILHO, 2006, p. 106-107), o escravo torna-se "uma mercadoria, objeto das mais variadas transações mercantis: venda, compra, empréstimo, doação, transmissão por herança, penhor, seqüestro, embargo, depósito, arremate e adjudicação. Era uma propriedade.”.

Giacomini (1988), ao analisar a história da escravidão brasileira, mostra que os efeitos da escravidão foram diferentes para os homens e para as mulheres. Segundo a autora (1988), as relações entre senhor-escravo e senhora-escrava se realizaram de forma a exercer o poder pela força; já, nas relações entre senhor-escrava, o poder era pela sexualidade. Baseavam-se na violência, como forma de punição, as relações entre senhora-escrava, uma vez que a escrava "seduzia" o senhor. A escrava, além do trabalho, também deveria oferecer o corpo, tanto como ama de leite, como como amante:

Pois a negra é coisa, pau para toda obra, objeto de compra e venda em razão de sua condição de escrava. Mas é objeto sexual, ama de leite, saco de pancada das sinhazinhas, porque além de escrava é mulher, evidentemente essa maneira de viver a chamada "condição feminina" não se dá de fora da condição de classe e mesmo de cor (GIACOMINI, 1988, p. 87-88).

Souza (2003) salienta que o tema do conflito entre senhores e escravos tem sido objeto de polêmica no campo da historiografia brasileira sobre a escravidão. $O$ antagonismo existe em relação à atitude do negro perante o sistema escravocrata:

\begin{abstract}
De um lado, posicionam-se historiadores, sociólogos, antropólogos e economistas que descrevem o escravo como um instrumento passivo diante do domínio dos senhores brancos.

De um outro lado, contrapõe-se a abordagem do negro como um agente ativo que se rebela contra o escravismo. Destruir, portanto, a perspectiva histórica de que os escravos não lutaram contra o cativeiro é o mote fundamental deste discurso de reação. Neste plano, a estratégia é transformar em mito a passividade do negro e estabelecer a resistência e o ativismo dos escravos como a verdade histórica (SOUZA, 2003, p. 59, grifos do autor).
\end{abstract}

Silva Filho (2006, p. 110-111) defende a história dos negros do Brasil como uma história de luta, em vez da submissão, da aceitação da condição de escravos, os negros do Brasil vivenciaram aspectos multifacetados de resistência durante a escravidão e no pós-escravidão:

Em diversos momentos os cativos empreenderam fugas, construíram quilombos, organizaram mocambos, realizaram levantes, protestos e motins. Quando libertos, se organizaram em irmandades religiosas; em movimentos sociais e artísticos; em centros de cultura, lazer e educação, numa demonstração inequívoca de insatisfação com a sua condição de vida (SILVA FILHO, 2006, p. 110-111, grifos do autor). 
Mesmo após liberto, o negro ocupou uma posição que, pelo discurso dominante, naturaliza seu lugar à margem. Das senzalas, passa a ocupar os cortiços, as favelas nas áreas urbanas. Como mostram Fernandes, Pereira e Nogueira (2005-2006, p. 174):

\begin{abstract}
A discriminação que se pratica no Brasil é parte da herança social da sociedade escravista. No mundo em que o "negro" e o "branco" se relacionavam como escravo e senhor, este último tinha prerrogativas que aquele não possuía - nem podia possuir - como "coisa" que era e "fôlego vivo", uma espécie de "instrumento animado das relações de produção". A passagem da sociedade escrava para a sociedade livre não se deu em condições ideais. Ao contrário, o negro e o mulato viram-se submergidos na economia de subsistência, nivelando-se, então, com o "branco" que também não conseguia classificar-se socialmente, ou formando uma espécie de escória da grande cidade, vendo-se condenados à miséria social mais terrível e degradante (FERNANDES; PEREIRA; NOGUEIRA, 2005-2006, p. 174).
\end{abstract}

A história do negro é permeada por lutas por uma posição legitimada pela sociedade que não seja somente a de bandido, de marginal, de favelado. Os movimentos negros de antes e os atuais buscam romper com um imaginário que segrega o negro, que não lhe permite ser sujeito de direitos, que o coloca como criminoso, como responsável pela violência que sofre. Há, pelos movimentos sociais de luta pelo negro, uma tentativa de interpelar a sociedade com um discurso que mostra o negro como cidadão, que não merece ser morto pela polícia simplesmente por ser "preto e pobre", por um dia ter tido seus antepassados como escravos. Embora funcione na sociedade um lugar ao negro à margem (terrível e degradante), este resiste e busca ocupar espaços além dos limites das favelas e dizer-se sujeito de direitos. Mesmo sendo segregado, o negro busca resistir ao genocídio que tanto se repete como um efeito naturalizado e legitimado em relação à população negra.

Marcamos ainda que, no espaço tenso e móvel das relações de poder entre o negro, a polícia, o Estado, a resistência se coloca e cresce, ainda que de forma interditada e silenciada. É possível dizer que a voz dos negros foi silenciada em traços de sua fundação: negação do nome próprio, da religião, das crenças e dos falares; no entanto, os quilombos fizeram acontecimento no discurso em que a regularidade da dominação se mantinha cristalizada. As fugas, as lutas corporais para fugir à senzala e ao capitão do mato, além das subidas de morros e montanhas para fundar comunidades libertas, indiciam que a resistência estava em curso, e foi dita do modo possível dentro daquelas condições sócio-históricas. $\mathrm{O}$ jogo tenso entre submissão e resistência não foi encerrado com a inscrição dos quilombos, mas produziu-se uma fenda nos efeitos escravagistas tão solidificados pela ideologia dominante; e os sentidos em disputa ainda podem ser ouvidos hoje, como vemos na morte de Cláudia da Silva Ferreira.

\title{
4 DA VIOLÊNCIA À HUMANIZAÇÃO: O CLAMOR DE "SOMOS TODXS CLÁUDIA"
}

Era 16 de março de 2014, quando Cláudia da Silva Ferreira, ao ir à padaria, foi baleada em uma operação da Polícia Militar. Alguns relatam que Cláudia foi morta por uma bala perdida; outros sustentam que ela foi morta após ter sido arrastada por uma viatura da Polícia Militar que prestava "socorro" à vítima. A partir desse fato, inúmeros 
textos noticiando o ocorrido ou protestando contra surgiram, e o ciberespaço funciona como um espaço em que esses dizeres contraditórios se confrontam. De um lado, os dizeres da mídia que defendem "o socorro policial"; de outro, os movimentos sociais que sustentam mais um crime realizado pela polícia contra uma "mulher, negra, faxineira, moradora da periferia do Rio de Janeiro, mãe de 4 filhos" (Marcha das Vadias de Recife, 17 de março de 2014).

A polícia, nas diferentes postagens em circulação nas páginas do Facebook da Marcha das Vadias, é vista na posição de um algoz, que é capaz de atrocidades "arrastada como se fosse um saco pela viatura da PM" (fala de um dos filhos de Cláudia) - contra a população que deveria proteger:

Figura 2 - Marcha das Vadias de Recife (17 de março de 2014)

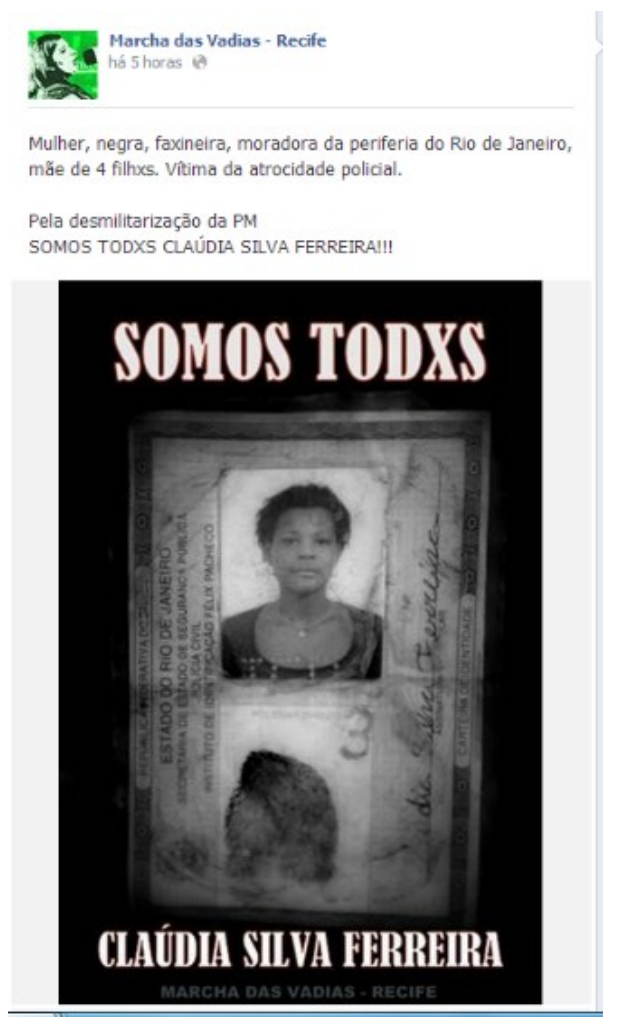

Ao colocarem o RG de Cláudia, os movimentos sociais, aqui a Marcha das Vadias, buscam mostrar que ela era uma cidadã brasileira, que teve seus direitos violados pela polícia militar. O documento nacional de identificação inscreve o efeito de legalidade de Cláudia e de reconhecimento de sua condição de cidadania, o que passa pela oficialidade do que poderíamos definir como discurso jurídico. Além disso, aponta que a vítima tem nome e não é simplesmente "mulher", "arrastada" como a mídia buscou retratar e como fica marcado, na trama da língua, um modo de não atribuir direitos a ela. "Arrastada" é uma denominação que tampona o direito à vida garantido por documentos oficiais dentro e fora do país, e fecha a possibilidade de se dizer de outros modos, "violentada, assassinada", por exemplo. 
O discurso em circulação na Marcha das Vadias sustenta que não há cidadania para o sujeito negro, principalmente no caso de Cláudia, em que ela é retratada como mais um na estatística, sem nomeação, sem humanização:

\begin{abstract}
Mulher, mulher, mulher, moradora, moradora, morta, morta, arrastada, arrastada, arrastada. Filha da arrastada, enterro de arrastada, viúvo de mulher, mulher arrastada. Assim mesmo: sem nome, sem identidade. SEM HUMANIDADE. APENAS MAIS UM CADÁVER, APENAS MAIS ESTATÍSTICA (Rede de Comunidades e Movimentos contra a Violência, compartilhamento da Marcha das Vadias de São Paulo em 17 de março de 2014).
\end{abstract}

Como salienta Mariani (2007, p. 103), refletindo sobre o nome próprio, a nomeação remete ao discurso eurocêntrico que aponta para as distinções sociais, para as diferentes linhagens de nobreza, ou seja, para a origem de classe social. Nas palavras de Mariani (2007, p. 103):

\begin{abstract}
Dar um nome próprio na cultura europeia (e por que não dizer ocidental) configura um ato de linguagem que confere identidade ao indivíduo. Assim sendo, atribuir um nome próprio associado a um nome de família e batizar de acordo com os preceitos cristãos, são atos de linguagem, dizeres que significam visando atribuir identidade unívoca, ou ainda, conferir uma individuação ligada a uma linhagem (MARIANI, 2007, p. 103).
\end{abstract}

Os discursos da mídia - funcionando como um acontecimento jornalístico acabam, ao não nomear a vítima, negando a identidade do sujeito negro, não há uma individuação. O sujeito é só mais um número no genocídio do negro. Os movimentos sociais sustentam um discurso de humanização do ser negro, e da mulher em especial. Como destacam, a mídia retrata o negro como coisa, bandido, culpado, sensacionaliza a barbárie, e os movimentos tentam romper com essa memória, ressaltando o lado humano, sonhador, corajoso, mas também doloroso e temeroso do sujeito negro brasileiro.

A convite do site feminista Think Olga - esse convite circula em algumas páginas do Facebook da Marcha das Vadias e também de outros coletivos feministas, como o Acontece Comigo -, diversas pessoas (artistas) passaram a enviar imagens que retratam Cláudia com "sensibilidade". Os movimentos, em uma forma de cibermilitância, filiamse a um discurso de inscrição da dignidade e da humanidade da mulher, que foi roubada por "criminosos", no caso de Cláudia, pela polícia. Esse discurso de resgate é entrecortado por um discurso do afeto (carinho) à população negra - "Por isso, nos propusemos a retratar Cláudia com mais carinho do que o visto nos últimos dias" (Think Olga.com) - como faixas que prestam homenagem a mortos em dizeres de luto, de reconhecimento e de justiça: 
Figura 3 - Retrato de Cláudia por Aline Valek

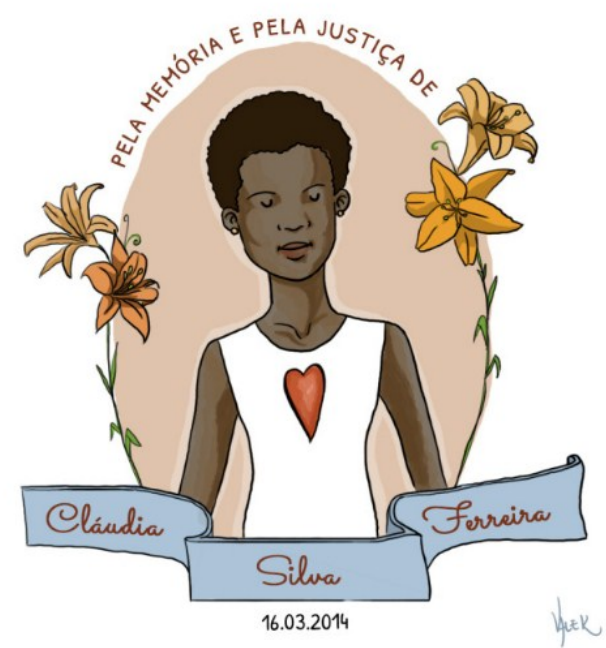

Figura 4 - Retrato de Cláudia por Tailor

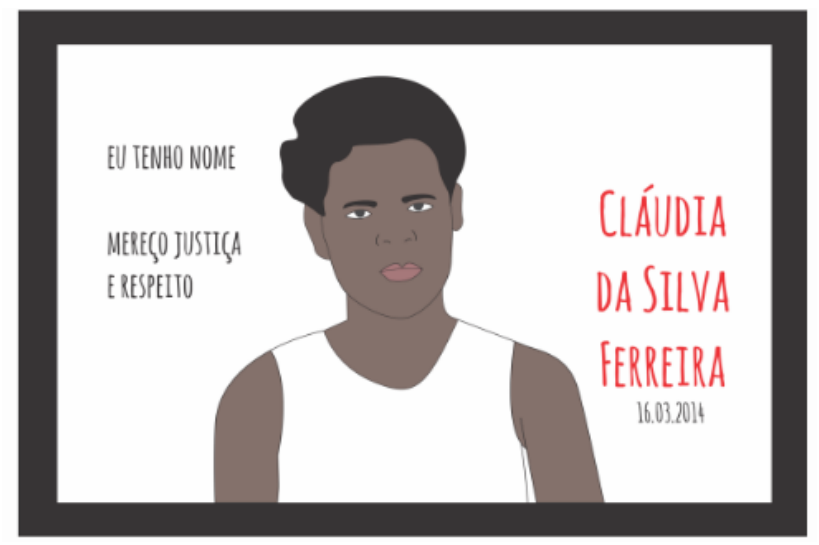

Como "guerreira", "extrovertida", "determinada", como um sujeito com nome, Cláudia é retratada por artistas que aceitam o convite do Think Olga. Ao desenharem Cláudia, buscando eternizar sua memória, as imagens e os movimentos sociais clamam por justiça. Todos os recortes acima humanizam a mulher, que antes tinha sido denominada como "arrastada", em geral adjetivo que é atribuído a objetos ou coisas. Cláudia passa a ser falada como mulher, como presença feminina cheia de atributos e dona de inúmeras qualidades, o que a apresenta, na rede digital, como mulher e cidadã. O enunciado "Somos todxs Cláudia" produz discursivamente o efeito desse laço imaginário pela via do direito à vida e da cidadania, o que faz falar os sentidos de "justiça". "Era só mais um Silva" 5 (nome comum, sujeito comum), mas sua morte produz acontecimento e simboliza a luta por uma humanização do negro e por uma criminalização e desmilitarização da polícia:

\footnotetext{
${ }^{4}$ Em <www.thinkolga.com>. Acesso em 09 fev. 2015.

${ }^{5}$ Em $<$ www.thinkolga.com>. Acesso em 09 fev. 2015.
} 
CLÁUDIA DA SILVA FERREIRA não foi arrastada por uma viatura. Ela foi ASSASSINADA POR POLICIAIS.

CLÁUDIA DA SILVA FERREIRA não foi vítima de uma circunstância, de um excesso policial.

CLÁUDIA FOI ASSASSINADA POR UMA INSTITUIÇÃO QUE MATA NEGROS E POBRES TODOS OS DIAS.

PELA DESMILITARIZAÇÃO DA POLÍCIA. (Rede de Comunidades e Movimentos contra a Violência, compartilhamento da Marcha das Vadias de São Paulo em 17 de março de 2014).

Há uma relação entre o poder estatal, representado pela polícia, e a mídia. Nos dizeres compartilhados pela Marcha das Vadias, a mídia, "encobrindo e escamoteando" os fatos (Compartilhamento da Marcha das Vadias de São Paulo), sustenta uma posição à polícia como salvadora. A Marcha das Vadias e os movimentos sociais de luta contra a violência buscam sustentar outro dizer, o qual coloca a polícia como criminosa dizeres esses escritos em maiúsculas como forma de grito a ecoar na sociedade. Por fim, esses enunciados sustentam não a imagem da polícia como protetora, mas sim como assassina, que comete excessos. A polícia, pelos dizeres dos coletivos, é uma instituição que "mata negros e pobres todos os dias", é "responsável pelo genocídio do povo negro e pobre". Mesmo a mídia sustentando o contrário - "a polícia tentou socorrer a vítima", dando outra interpretação ao fato - os movimentos sociais atualizam esse dizer e instauram um outro, mostrando o quão perversa é a corporação militar. Como instrumento repressor do Estado, a polícia age sustentando uma brutalidade contra o negro e legitimando uma violência (história) contra esse sujeito.

\section{CONSIDERAÇÕES FINAIS: UM ACONTECIMENTO DISCURSIVO}

Com essa análise, procuramos mostrar como, no entrecruzamento de enunciados, um acontecimento discursivo é apreendido. Nos posts divulgados nas páginas do Facebook da Marcha das Vadias, o acontecimento está em humanizar a população negra, aqui representada por Cláudia, e culpabilizar a polícia, o Estado. A luta é pela vida dos negros, dos segregados e não pelo seu genocídio. A militância consiste em fazer com que a sociedade clame pela vida dos negros e não espetacularize sua morte.

Hoje não mais o navio negreiro, hoje são as viaturas policiais que dizimam negros brasileiros, como nos diz Orlandi (2009, p. 227): "segregado é aquele que não tem direito de existir. É o sujeito à extinção". Assim, alguns dizeres significam o negro no Brasil, como um sujeito a ser dizimado. Contudo, este resiste e impõe-se à sociedade. Sua morte, não mais pela chibata, produz acontecimento e ainda faz ecoar gritos que dizem "somos todxs Cláudia pela humanização do negro no Brasill”. 
BEAUVOIR, S. de. O segundo sexo. Fatos e mitos. São Paulo: Difusão Européia do Livro, [1949] 1970. DELA-SILVA, S. C. Do acontecimento jornalístico ao discursivo: o discurso sobre a televisão no Brasil. In: AZEVEDO, N. P. da S. G. de; FONTE, R. F. de (Orgs.). Análise do Discurso: mo(vi)mento de intepretações. Curitiba: CRV, 2011.

FERNANDES, F.; PEREIRA, J.B.B.; NOGUEIRA, O. A questão racial brasileira vista por três professores. Revista USP, São Paulo, n. 68, p. 168-179, dez.-fev., 2005-2006.

FLORENTINO, M. Em costas negras. São Paulo: Companhia das Letras, 1997.

GARCIA, D. A.; SOUSA, L. M. A. e. Ler o arquivo hoje: a sociedade em rede e suas andanças no ciberespaço. Conexão Letras. A noção de arquivo em Análise de Discurso: relações e desdobramentos, Porto Alegre, v. 9, n. 11, p. 83-97, 2014.

GIACOMINI, M.S. Mulher e escrava: uma introdução histórica ao estudo da mulher negra no Brasil. Petrópolis: Vozes, 1988.

GUILHAUMOU, J.; MALDIDIER, D. Efeitos do arquivo. A análise do discurso ao lado da História. In: ORLANDI, E. P. (Org.). Gestos de leitura: da história no discurso. Campinas: Editora da Unicamp, 1993. MATTOSO, K.M.Q. Ser escravo no Brasil. São Paulo: Brasiliense, 1982.

MARIANI, B. Quando as línguas eram corpos: sobre a colonização linguística portuguesa na África e no Brasil. In: ORLANDI, E.P. (Org.) Política linguística no Brasil. Campinas: Pontes, 2007.

ORLANDI, E.P. Espaço de violência: o sentido de delinquência. Cadernos de Estudos Linguísticos, Campinas, v. 51, n. 2, jul.-dez., 2009.

PÊCHEUX, M. Discurso: estrutura ou acontecimento. Campinas: Pontes, 1990.

SILVA FILHO, J. B. da. História do negro no Brasil. Cadernos PENESB - Periódico do Programa de Educação sobre o negro na sociedade brasileira - FEUFF, Rio de Janeiro/Niterói, n. 7, p. 102-134, nov. 2006.

SOUZA, P. A boa nova da memória anunciada: o discurso fundador da afirmação do negro no Brasil. In: ORLANDI, E.P. (Org.). Discurso fundador: a formação do país e a construção da identidade nacional. Campinas: Pontes, 2003.

ZOPPI-FONTANA, M. Cidadãos modernos. Campinas: Editora da Unicamp, 1997.

Recebido em: 26/05/14. Aprovado em: 19/12/14.

Title: "All of us are Claudia": the legitimation of state violence

Authors: Dantielli Assumpção Garcia; Lucília Maria Abrahão e Sousa

Abstract: This text, from the theoretical perspective of Pêcheux's Discourse Analysis, examines some posts published on Marcha das Vadias (The SlutWalk) Facebook pages on the murder of Cláudia da Silva Ferreira after being dragged by a military police vehicle on March 16 ${ }^{\text {th }}, 2014$, in Rio de Janeiro. Making use of the notion of discursive event, we clarify how a memory about both black people and the police in Brazil is updated, portraying the latter as guilty for the murder of black people and the former as victims of a segregationist society. Also, we elucidate how there is, in the posts, an attempt to break away from the violence produced and legitimized by the state.

Keywords: Blackpeople. Police. discursive event.

Título: "Somos todxs Cláudia": la legitimación de la violencia por el Estado

Autores: Dantielli Assumpção Garcia; Lucília Maria Abrahão e Sousa

Resumen: Este texto, en la perspectiva teórica del Análisis del Discurso de Pêcheux, analiza algunos posts publicados en las páginas del Facebook de la Marcha das Vadias (Marcha de las rameras) sobre el asesinato de Cláudia da Silva Ferreira después haber sido arrastrada por un vehículo de la Policía Militar en 16 de marzo de 2014, en Rio de Janeiro. Movilizando la noción de acontecimiento discursivo, mostramos cómo se actualiza una memoria sobre el negro y la policía en Brasil, colocando esta como culpable por el asesinato de la población negra y aquél como víctima de la sociedad segregacionista. Explicitamos como, en los posts, hay la tentativa de una ruptura en la violencia producida y legitimada por el Estado.

Palabras-clave: Negro. Policía. Acontecimiento discursivo. 